J. Gen. Appl. Microbiol.

Vol. 5, Nos. 1 2, 1959

\title{
TAXONOMICAL STUDIES OF THE STREPTOMYCES PRODUCING ANTIMYCIN A-BLASTMYCIN GROUP ANTIBIOTICS
}

\author{
KEIKO KARASAWA, NOBUO TANAKA, HIROSHI YONEHARA \\ and HAMAO UMEZAWA \\ The Institute of Applied Microbiology, University of Tokyo \\ Received for publication, January 25, 1959
}

In the series of screening tests of new antibiotics effective against Piricularia oryzae (a causative agent of rice plant disease), a number of strains of streptomyces, producing antimycin A, blastmycin or other similar substances, were isolated in our laboratory since 1955. Antimycin A (1) and blastmycin (5) are similar in chemical, physical and biological properties. Antimycin A-producing strains produce four kinds of antibiotics, i.e. antimycin $A_{1}, A_{2} A_{3}$, and $A_{4}(2,3)$; whereas blastmycin-producing ones produce a single antibiotic (5). Blastmycin is most closely related to antimycin $A_{3}$. Both substances give the same molecular formula of $\mathrm{C}_{26} \mathrm{H}_{33} \mathrm{~N}_{2} \mathrm{O}_{9}$ and melting point $167-168^{\circ}$. However characteristic difference in the infrared absorption spectra indicates that they may be isomers $(6)$. The descriptions of some of the morphological, physiological and serological characteristics of the cultures of the strains, producing antimycin A, blastmycin and/or other anti-piricularia substances, will be presented in this publication.

\section{STRAINS}

The following 14 strains of anti-piricularia substance sources were isolated and studied in our laboratory.

Antimicin A-producing streptomyces: two strains-No. 2A-720 (4), No. 73-2.

Blastmycin-producing streptomyces: four strains--No. 455-D (5), No. 709$\mathrm{A}_{1}$, No. $723-\mathrm{A}_{1}$, No. $737-\mathrm{F}_{2}$.

Antimycin A or/and blastmycin-producing streptomyces: two strains-No. 295-D ${ }_{1}$ No. 612-B B $_{1}$

Unidentified antipiricularia substance(s)-producing streptomyces: six strains-No. $1075-B_{4}$, No. $1082-F_{1}$, No. $1085-B_{1}$, No. $1087-B_{1}$, No. $1088-H_{1}$, No. 1099-B B $_{3}$.

The morphological and physiological characteristics.

The aerial mycelium of these streptomyces are powdery, white at first, changing to gray on certain media. The vegetative myceliums are light 
brown to dark brown. Dark brown soluble pigments are produced in organic media. In synthetic agars antimycin A-producing strain forms brown soluble pigments, but blastmycin-producing strains form none or trace of brown pigment.

The aerial hyphae, ranging from 1.0 to $1.5 \mu$ in cross diameter, have many branches. Some strains form spirals on some media, and others no spirals. Distal portions of the aerial filaments subdivide into spore chains, and the conidia are oval or spherical, ranging 1.0 to 1.3 by 1.0 to $1.5 \mu$ in size.

Because of dark brown pigment production in organic media, this group of the organisms is expected to belong to group II-1 (chromogenic type) of the genus streptomyces in Waksman and Henrici's key. On the basis of the above-mentioned characteristics of the myceliums these microbes seem to occupy positions adjacent to Streptomyces olivochromogenus and/or Streptomyces flavochromogenes.

Comparative studies of blastmycin-prodcing organisms and antimycin A-producing one.

The morphological, and physiological characteristics of the cultures were comparatively examined, simultaneously grown on the same media. The characteristics on synthetic media (glycerol CzAPEK's agar) and organic media (yeast extract agar), utilization of carbon sources, hydrolysis of starch, peptonization of milk, and liquefaction of gelatin are presented in Table 1 . The antimycin A-producing microbe can be differentiated from the group of blastmycin-producing organisms in hydrolysis of starch, peptonization of milk and other properties. Four strains of blastmycin-producing organisms subdivide into two groups B-1 (No. $455-\mathrm{D}_{1}$ and No. $737-\mathrm{F}_{2}$ ) and B-2 (No. 709- $\mathrm{A}_{1}$ and No. $723-A_{1}$ ). The former group produces no or few spirals, but the latter abundant spirals on certain media. The production of soluble pigment and pigment in the mycelium is most abundant in the antimycin A-producing organism. In the blastmycin-producing microbes those of group B-2 form more pigment in the mycelium and medium than those of group B-1 do.

As shown in Table 2 the utilization carbon sources is markedly different among these three groups.

Serological comparisons of the antigenic structures of the microbial cells.

The antigenic structures of these four organisms were comparatively studied by means of precipitin reactions combined with absorption technique.

The preparation of antigen solutions and the serological reactions were carried out in the same methods as described in the previous paper ( 7 ).

\section{Precipitin reactions (Ring tests)}

As summarized in Table 3, the antigen solution of the strain No. 2A-720 showed positive $(1 \mathrm{ml}$ of the undiluted antigen solution precipitin reactions 
Table. 1. Morphological and physiological characteristics of the antimycin A-producing strain and blastmycin-producing strains.

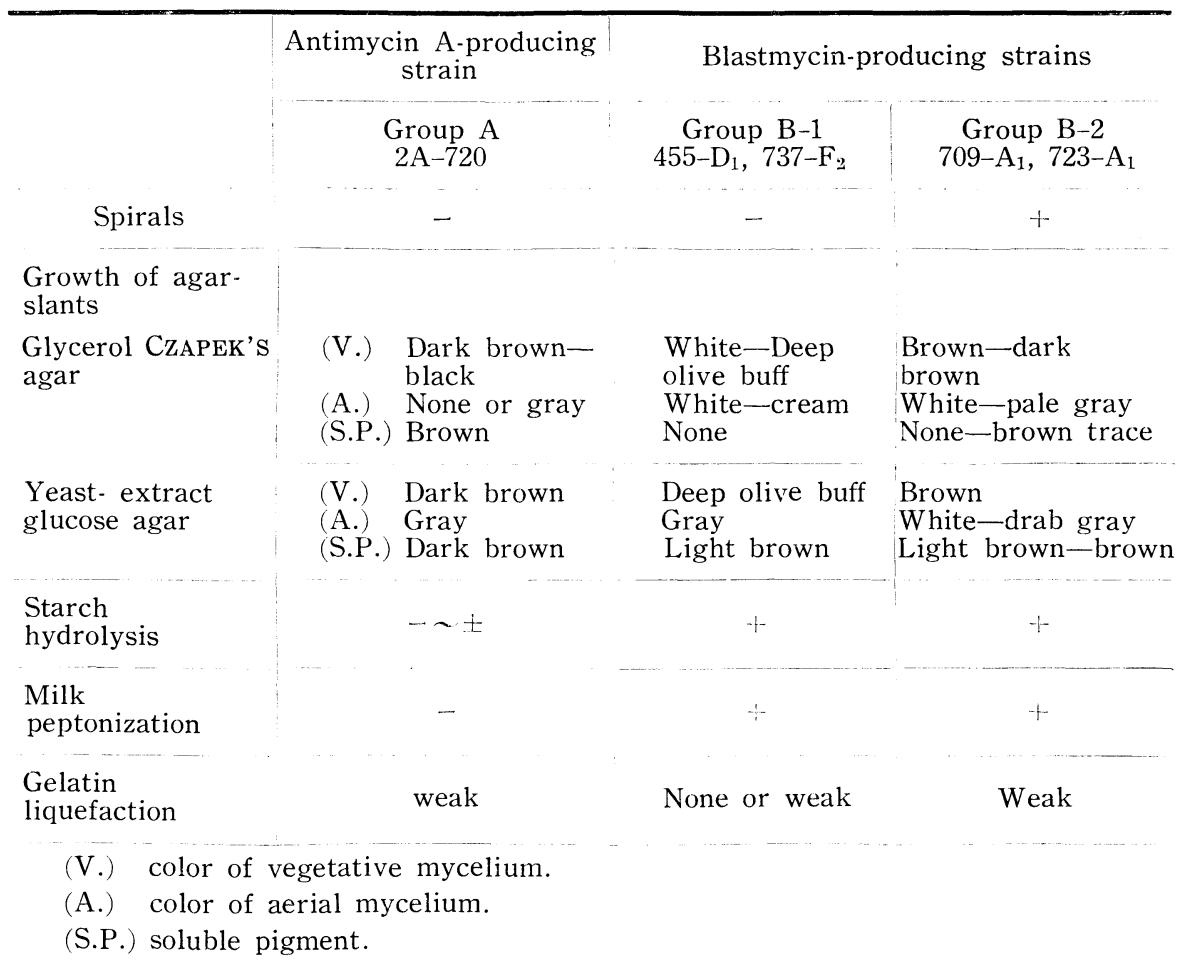

Table 2. The utilization of carbon compounds of the antimycin A-producing strain and blastmycin-producing strains.

\begin{tabular}{lcccc} 
& Group A & Group B-1 & Group B-2 \\
\hline D-Xylose & $(-)$ & - & + \\
L-Arabinose & $\ddots$ & + & - \\
L-Rhamnose & - & - & + \\
D-Fructose & $(-)$ & $+-(-)$ & $+\sim$ \\
Sucrose & - & $(-)$ & $+\sim-$ \\
Maltose & +- & $(-)$ & + \\
Lactose & + & $(-)$ & + \\
Raffinose & + & - & +- \\
Mannitol & - & - & +- \\
Inositol & + & $+-(-)$ & $+(-)$ \\
Salicin & - & - & \\
4.: good growth. & & \\
(-): poor growth. & & \\
$-:$ no growth. &
\end{tabular}


was obtained from $100 \mathrm{mg}$ of the wet mycelial mass) up to the dilution of 1:3,200 with homologous antiserum, 1:800 with anti-455- $\mathrm{D}_{1}$ serum, 1:400 with anti-709- $\mathrm{A}_{1}$ serum, and 1:800 with anti-723- $\mathrm{A}_{1}$ serum. The antigen solutions of blastmycin-producing organisms No. $455-\mathrm{D}_{1}$, No. $709-\mathrm{A}_{1}$ and No. $723-\mathrm{A}_{1}$ demonstrated positive reactions from $1: 10$ to $1: 1,600$ with both homologous and heterologous antiserums. By the method employed marked cross reactions were demonstrated among the mycelial antigens of these microorganisms.

Table 3. Precipitin reactions of the mycelial antigens of the strains No. $2 \mathrm{~A}-720$. No. $455-\mathrm{D}_{1}$, No. $709-\mathrm{A}_{1}$ and No. $723-\mathrm{A}_{1}$

\begin{tabular}{|c|c|c|c|c|}
\hline Antigen & Group A & Group B-1 & \multicolumn{2}{|c|}{ Group B-2 } \\
\hline Antiserum & $2 \mathrm{~A}-720$ & $455-\mathrm{D}_{1}$ & $709-\mathrm{A}_{1}$ & $723-\mathrm{A}_{1}$ \\
\hline anti-2A-720 & 3,200 & 800 & 200 & 10 \\
\hline anti-455- $\mathrm{D}_{1}$ & 800 & 1,600 & 200 & 10 \\
\hline anti-709- $\mathrm{A}_{1}$ & 400 & 400 & 800 & 200 \\
\hline anti-723- $\mathrm{A}_{1}$ & 800 & 800 & 800 & 400 \\
\hline
\end{tabular}

The numbers represent reciprocals of the highest dilution of the mycelial antigen solution ( $1 \mathrm{ml}$ of undiluted solution was extracted from $100 \mathrm{mg}$ of the wet mycelial mass) which showed positive precipitin reactions with the antiserums.

\section{Absorption tests in precipitin reaction (Ring tests)}

The marked cross reactions between antimycin A-producing organism and blastmycin-producing ones led us to the further studies of the antigenic structures of the mycelial cells by means of absorption tests. Anti-2A-720 serum was absorbed with acetone-treated mycelial mass of the strain No. 455- $\mathrm{D}_{1}$ twice or three times until the antiserum did not show and precipitin reactions with the antigen solution of the strain No. $455-\mathrm{D}_{1}$. After the absorption the antiserum still showed positive precipitin reactions with the homologous antigen solution. After absorption of anti-455- $\mathrm{D}_{1}$ serum with the acetone-treated mycelial mass of No. 2A-720, the antiserum showed positive precipitin reaction up to the dilution of $1: 200$ with the homologous antigen solution. By this way it was observed that both organisms contain their specific antigens, although they have certain common antigens. Absorption tests were carried out among three strains $\left(2 \mathrm{~A}-720,455-\mathrm{D}_{1}\right.$ and 709- $\mathrm{A}_{1}$ ), and the results are summarized in Table 4. It indicates the antigenic relationship of the three organisms as following: Each microbe contains its own specific antigen(s), although certain antigen(s) is distributed in all of them. Another common antigen or antigens of $2 \mathrm{~A}-720$ and $455-\mathrm{D}_{1}$ may lack in the mycelium of $709-A_{1}$. The mycelial cells of $2 \mathrm{~A}-720$ may not contain the third common antigen(s) of $455-\mathrm{D}_{1}$ and $709-\mathrm{A}_{1}$.

\section{Precipitin reactions in agar (OuCHTERLONY's gel diffusion techninue)}


Table 4. Absorption tests in precipitin reaction of the mycelial antigens of the strains No. $2 \mathrm{~A}-720$, No. $455-\mathrm{D}_{1}$ and No. $709-\mathrm{A}_{1}$.

\begin{tabular}{|c|c|c|c|c|}
\hline \multirow[b]{2}{*}{ Antiserum } & \multirow{2}{*}{$\begin{array}{l}\text { Absorbing } \\
\text { antigen powder }\end{array}$} & \multicolumn{3}{|c|}{ Antigen solution } \\
\hline & & $\underset{2 \mathrm{~A}-720}{\text { Group }} \mathrm{A}$ & $\underset{455-\mathrm{D}_{1}}{\operatorname{Group}} \mathrm{B}-1$ & $\underset{709-A_{1}}{\text { Group }}$ \\
\hline anti-2A-720 & $\begin{array}{l}455-\mathrm{D}_{1} \\
709-\mathrm{A}_{1}\end{array}$ & $200(3,200)$ & ${ }_{10}^{0}(800)$ & ${ }_{0}^{0}(200)$ \\
\hline anti-455- $\mathrm{D}_{1}$ & $\begin{array}{l}2 \mathrm{~A}-720 \\
709-\mathrm{A}_{1}\end{array}$ & $0^{0}(800)$ & $200(1,600)$ & ${ }_{0}^{10}(200)$ \\
\hline anti-709- $\mathrm{A}_{1}$ & $\begin{array}{l}2 \mathrm{~A}-720 \\
455-\mathrm{D}_{1}\end{array}$ & $0^{(400)}$ & ${ }_{0}^{200}(400)$ & ${ }_{100}^{100}(800)$ \\
\hline
\end{tabular}

The numbers represent reciprocals of the highest dilution of the mycelial antigen solution ( $1 \mathrm{ml}$ of undiluted solution was extracted from $100 \mathrm{mg}$ of the wet mycelial mass) which showed positive precipitin reactions with the antiserum. Those in braketes are before absorption.

The experiments were performed in the 0.5 per cent agar containing $0.02 \mathrm{M}$ phosphate buffer ( $\mathrm{pH} 7.5$ ), $0.15 \mathrm{M} \mathrm{NaCl}$ and 0.005 per cent merthiolate. Four wells (10 mm diameter) were placed in the shape of square, equidistant (10 $\mathrm{mm}$ diameter) from the fifth one located in the center. The central one was filled with undiluted antiserum and the outside ones with the antigen solutions $(1: 10)$ of the three streptomyces and saline. They were allowed to diffuse and observed for two weeks or longer until the precipitin bands were completely formed.

As illustrated in Figure 1, there seem to exsit a couple of common precipitin bands of No. 2A-720, No. $455-\mathrm{D}_{1}$ and No. $709-\mathrm{A}_{1}$, a couple of common precipitin bands of No. $2 \mathrm{~A}-720$ and No. $455-\mathrm{D}_{1}$, three specific precipitin bands of No. 2A-720 and three specific precipitin bands of No. $455-\mathrm{D}_{1}$.

The strains No. 295- $D_{1}$ and No. 612- $B_{1}$

These two strains of streptomyces produce unidentified antifungal substances closely related to, if not identical with, antimycin A or blastmycin. The former strain is closely related to the strain No. 2A-720 (antimycinsource). The latter strain is identified with Streptomyces noboritoensis. From the viewpoint of production of soluble pigment, it seems to occupy the position between the strains No. 2A-720 and No. 455- $\mathrm{D}_{1}$ (blastmycin source). The mycelial extracts of these organisms demonstrated cross precipitin reactions with anti-2A-720 serum and anti-455- $\mathrm{D}_{1}$ serum. (see Table 5).

The strain No. 73-2

In the course of screening program of antifungal substances, a strain markedly different from the organisms described above was isolated. The 

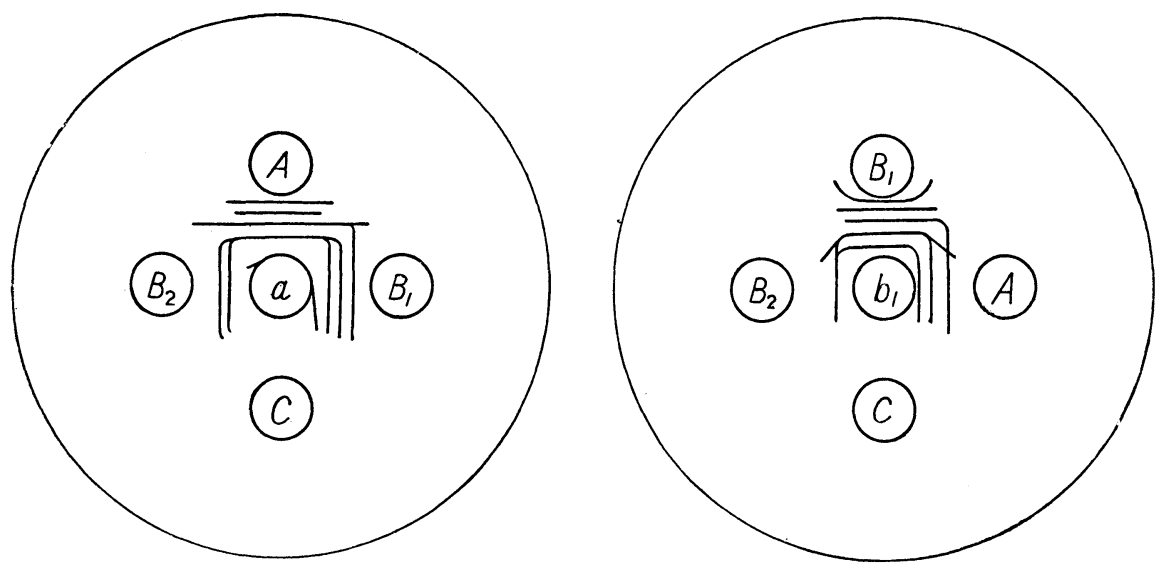

Fig. 1. Agar diffusion patterns of the mycelial antigen solutions of No. 2A-720, No. $455-\mathrm{D}_{1}$ and No. $709-\mathrm{A}_{1}$ towards anti-2A-720 serum and anti-455- $\mathrm{D}_{1}$ serum.

a: anti-2A-720 serum.

$\mathrm{b}_{1}$ : anti-455- $\mathrm{D}_{1}$ serum.

A: mycelial antigen solution of 2A-720.

$\mathrm{B}_{1}$ : mycelial antigen solution of $455-\mathrm{D}_{1}$

$\mathrm{B}_{2}$ : mycelial antigen solution of $709-\mathrm{A}_{1}$

C: saline.

Table 5. Morphological and physiological characteristics of the Antimycin A or/and blastmycin-producing strains.

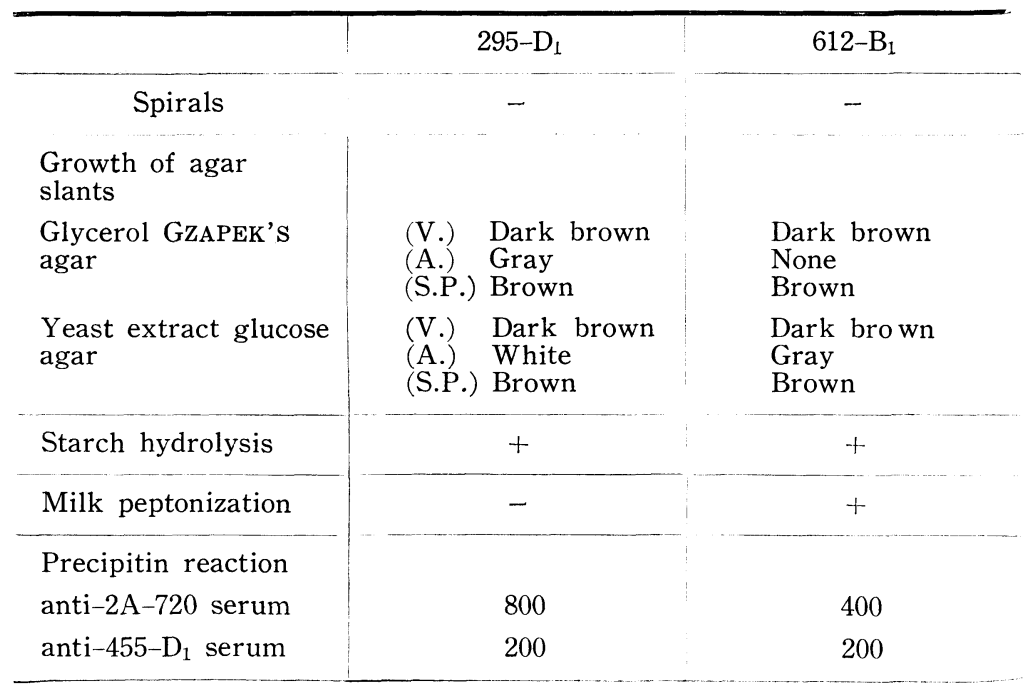

(V.) color of vegetative mycelium.

(A.) color of aerial mycelium.

(S.P.) soluble pigment. 
Table 6. Morphological and physiological characteristics of the antimycin-producing strain No. 73-2.

\begin{tabular}{|c|c|c|c|}
\hline Medium & V. & A. & S.P. \\
\hline KRAINSKY's agar & White-dark brown & Pale gray & None \\
\hline Starch agar & Pale brown & White-pale gray & None \\
\hline Glycerol CzAPEK's agar & Yellowish brown & Water-green & None \\
\hline Ca-malate glycerol agar & $\begin{array}{c}\text { Colorless-pale } \\
\text { brown }\end{array}$ & White-pale gray & None \\
\hline Ca-citrate glycerol agar & $\begin{array}{c}\text { Colorless-pale } \\
\text { brown }\end{array}$ & White-pale gray & None \\
\hline $\begin{array}{l}\text { Yeast-extract } \\
\text { glucose agar }\end{array}$ & $\begin{array}{c}\text { Colorless-dark } \\
\text { brown }\end{array}$ & Water-green & $\begin{array}{c}\text { Brown } \\
\text { trace }\end{array}$ \\
\hline Meat-extract peptone agar & Colorless-brown & Pale gray & None \\
\hline Potato plug & Cream & White & \\
\hline Carrot plug & Cream & White & \\
\hline Starch hydrolysis & + & & \\
\hline Gelatin liquefaction & + & & \\
\hline $\begin{array}{l}\text { Milk coagulation and } \\
\text { peptonization }\end{array}$ & + & & \\
\hline $\begin{array}{l}\text { LOEFFIER'S serum medium } \\
\text { liquefaction }\end{array}$ & + & & \\
\hline
\end{tabular}

(V.) color of vegetative mycelium.

(A.) color of aerial mycelium.

(S.P.) soluble pigment.

Table 7. The utilization of carbon compounds of the strain No. 73-2.

\begin{tabular}{lc|lr}
\hline D-Xylose & + & Inulin & - \\
L-Xylose & + & Starch & + \\
L-Ramnose & - & Mannitol & + \\
D-Fructose & + & Sorbitol & $(-)$ \\
Garactose & + & Dulcitol & $(-)$ \\
D-Glucose & + & Inositol & - \\
Sucrose & $(-)$ & Salicin & + \\
Maltose & + & Na-acetate & $(-)$ \\
Raffinose & - & Na-citrate & $(-)$ \\
L-Arabinose & $(-)$ & Na-succinate & $(-)$ \\
$\quad+:$ good growth. & & \\
\multicolumn{2}{l}{ (-): poor growth. } & &
\end{tabular}


morphological and physiological characteristics of this strain is summarized in Tables 6 and 7. It appears to belong to the species Streptomyces griseus, because of powdery, white to water-green aerial mycelium, production of trace soluble pigment in organic media, strong hydrolysis of starch and gelatin, coagulation and peptonization of milk, and liquefaction of LOEFFLER's serum medium. The antifungal substances produced by this microbe was identified with antimycin A. The mycelial extract of this organism showed negative precipitin reactions with anti-2A-720 serum and anti-455- $\mathrm{D}_{\perp}$ serum.

\section{DISCUSSION AND SUMMARY}

The comparative studies on the morphological and physiological characteristics of the cultures of blastmycin and antimycin A sources indicated that most of the strains may be related to each other. This idea was confirmed by the marked cross precipitin reactions of these organisms. They may be classified into three groups A, B-1 and B-2. The antimycin Aproducing organism belongs to the former group and the blastmycin ones to the latter two groups. The absorption tests and Ouchterlony's gel diffusion methods suggested that three groups of the streptomyces may be serologically independant. The antigenic structure of the strain No. $455-\mathrm{D}_{1}$ appear to be more complicated than those of the strains No. 2A-720 and No. 709-A . They contain the specific antigen(s) and common antigen(s). A strain of antimycin A sources was observed to belong to the species Streptomyces griseus. It showed no cross precipitin reactions with the other organisms.

The authors should like to express their deep thanks to Prof. Yusuke Sumiki for his thoughtful directions in this study.

\section{REFERENCES}

(1) B. R. Dunshee, C. Leben, G. W. Keitt and F. M. Strong: J. Am. Chem. Soc., 71, 2436 (1949).

(2) H. G. Schneider, G. M. Tener and F. M. Strong: Arch. Biochem. \& Biophys., 37, 147 (1952).

(3) Y. Harada, K. Uzu and M. Arai: J. Antibiotics Ser. A, 11, 32 (1958).

(4) Y. Sakagami, S. Takeuci, H. Yonehara, H. Sakai and M. Takashima: Ibid. Ser. 9, 1 (1956).

(5) K. Watanabe, T. Tanaka, K, Fukuhara, N, Miyairi, H, Yonehara and H. UmezaWa: Ibid. Ser. A., 10, 39 (1957).

(6) H. Yonehara and S. TAKeuCI: Ibid. Ser. A, 11, 254 (1958).

( 7 ) N. Tanaka, K. Karasawa, N. Miyairi, N. Shinjo, T. Nishimura and H. UmeZAWA: J. Gen. Appl. Microbiol., 4, 259 (1958). 